\title{
Estado de frescor e qualidade higiênica do pescado vendido numa cidade do interior de Portugal
}

[Freshness and hygienic quality of fish sold in a portuguese town]

\author{
M.C. Fontes, A. Esteves, F. Caldeira, C. Saraiva, M. Vieira-Pinto, C. Martins \\ Centro de Estudos em Ciência Animal e Veterinária \\ Universidade de Trás-os-Montes e Alto Douro \\ Apartado 1013 \\ 5001-801 - Vila Real Codex - Portugal
}

\begin{abstract}
RESUMO
Avaliaram-se o estado de frescor e a qualidade higiênica do pescado disponível em alguns estabelecimentos comerciais de Vila Real, uma cidade do interior de Portugal. Vinte e três amostras foram submetidas a uma análise sensorial e a análises físico-químicas - determinação do teor de azoto básico volátil total (ABVT), do índice de refração do humor aquoso e do pH. A avaliação da qualidade higiênica do pescado foi feita por meio de diferentes análises microbiológicas na superfície e na profundidade do músculo do pescado. O pescado fresco, considerado por todos os métodos de análise, próprio para consumo, apresentou estado de frescor entre bom e satisfatório. O ABVT foi considerado o método objetivo de eleição, sempre que surgiram dúvidas relativamente ao grau de frescor do pescado. $\mathrm{O}$ pescado próprio para consumo apresentou valores que variaram entre os 20,60 e $27,36 \mathrm{mgN} / 100 \mathrm{~g}$ e perfil microbiológico aceitável, com contagens de microrganismos psicrotróficos entre 5,41 e $6,03 \mathrm{UFC} / \mathrm{cm}^{2} \mathrm{na}$ superfície e entre 4,79 e $5,28 \mathrm{UFC} / \mathrm{cm}^{2}$ no músculo.
\end{abstract}

Palavras-chave: pescado, frescor, higiene, análise sensorial, análise físico-química

\begin{abstract}
The freshness and hygienic quality of fresh fish sold in some fish markets of Vila Real, a Portuguese town, were evaluated. Twenty-three samples were examined by sensorial and physico-chemical analyses (total volatil basic nitrogen - TVBN, aqueous humour refraction rate and $\mathrm{pH}$ ). The determination of hygienic quality of fish was carried out by different microbiological analysis on the surface and deepness of fish muscle. Fish was considered proper for consumption by all the methods used in the evaluation of fish freshness, and was classified between good and satisfactory. TVBN was considered the objective method of election, in case of doubt about fish freshness, and fish proper for consumption presented TVBN values between 20.60 and $27.36 \mathrm{mgN} / 100 \mathrm{~g}$. The microbiological profile was considered acceptable with psychrotrophic microorganisms counts between 5.41 and $6.03 \mathrm{CFU} / \mathrm{cm}^{2}$ on fish surface and between 4.79 and $5.28 \mathrm{CFU} / \mathrm{g}$ in muscle deepness.
\end{abstract}

Keywords: fresh fish, freshness, higyene, sensorial analysis, physico-chemical analyses

\section{INTRODUÇ̃̃O}

A qualidade do pescado é, em grande parte, determinada pelo grau de frescor, cuja apreciação é feita com base em critérios subjetivos mediante exame organoléptico, que é o método utilizado pelos consumidores e o mais usado pelos Inspetores Sanitários (Baixas-
Nogueras et al., 2001). Há, contudo, a possibilidade de recorrer a metodologias objetivas (físicas e químicas) para avaliar o frescor do pescado. Segundo Nielson (1997), a análise sensorial continua a ser essencial, mesmo que se desenvolvam métodos instrumentais de fácil aplicação, pois fornece informação mais completa sobre o estado do pescado.

Recebido em 26 de março de 2007

Aceito em 17 de setembro de 2007

E-mail: mcfontes@utad,pt 
A regulamentação européia refere-se à determinação do azoto básico volátil total como sendo um método que permite determinar se o pescado está apto para consumo assim como quantificar o seu grau de alteração (Martin et al., 1997; Pons-Sánchez-Cascado et al., 2005). A determinação do $\mathrm{pH}$ muscular é usada com ressalvas, sendo, no entanto, uma metodologia de fácil e rápida execução. A determinação do índice de refração do humor aquoso é outra metodologia indicada e aumenta em função da deterioração do pescado (Martin, 1978). Farber (1965) sugere existir uma boa correlação entre o índice de refração do humor aquoso e a avaliação organoléptica.

As análises microbiológicas não fornecem informações acerca do frescor do pescado, mas permitem detectar a presença de bactérias patogénicas, de microrganismos indicadores de contaminação fecal ou até de eventuais práticas de manuseio deficientes (Huss, 1994; Matos, 1994).

Os objetivos deste trabalho foram avaliar o grau de frescor e a qualidade higiênica do pescado disponível em diferentes superfícies comerciais e comparar as diferentes técnicas usadas para avaliar o seu frescor.

\section{MATERIAL E MÉTODOS}

Ao longo de seis semanas foram visitados quatro estabelecimentos comerciais de Vila Real, uma cidade do interior de Portugal, tendo sido analisadas 23 amostras de carapau (Trachurus trachurus). Cada amostra constava de sete carapaus de tamanho médio $( \pm 180 \mathrm{~g})$ retirados aleatoriamente dos expositores. As amostras, mantidas em refrigeração $\left( \pm 8^{\circ} \mathrm{C}\right)$ ao longo do trabalho, foram analisadas em dois tempos. No dia de aquisição (T1), as amostras foram sujeitas às análises sensorial, físico-química e microbiológica. As análises sensorial e físicoquímica foram repetidas $48 \mathrm{~h}$ após a aquisição (T2).

A análise sensorial foi efetuada por um painel de provadores, formado por oito pessoas, em sala de provas especificamente projetada para esse fim, e sempre nas mesmas condições. Assim, a temperatura ambiente foi estabilizada a $20 \pm 3^{\circ} \mathrm{C}$ e a iluminação era exclusivamente artificial. As amostras foram classificadas quanto ao nível de intensidade detectado, para cada um dos parâmetros analisados, utilizando uma escala de nove valores. Os parâmetros avaliados foram escolhidos de acordo com a Norma Portuguesa (NP) 2287 (Pescado..., 1985a) e as tabelas de cotação do frescor dos peixes azuis referida no regulamento das Comunidades Européias (Regulamento..., 1996) e incluíram: a pigmentação, o brilho e a presença de muco na pele, a forma do olho e as características da córnea e da pupila, a cor e a presença de muco nas guelras, e a textura muscular, o cheiro e a apreciação global.

A determinação do azoto básico volátil total (ABVT) foi feita pelo método de Conway segundo a NP 2930 (Pescado..., 1985b). O índice de refração (IR) do humor aquoso foi verificado por leitura direta em refratômetro ${ }^{1}$ e o valor de $\mathrm{pH}$ foi determinado em potenciômetro ${ }^{2}$.

As análises microbiológicas incidiram na superfície e na profundidade muscular do pescado. Efetuaramse três zaragatoas, correspondendo cada uma a $10 \mathrm{~cm}^{2}$ da superfície cutânea do carapau (delimitadas com bitola esterilizada). Uma das zaragatoas foi submersa em $10 \mathrm{ml}$ de meio de enriquecimento para pesquisa de Listeria spp. (University of Vermont Medium com aditivo) ${ }^{3}$. Das outras duas, uma foi imersa em $10 \mathrm{ml}$ de solução triptona sal, para pesquisa de Staphylococcus coagulase positivo $\left(\mathrm{em} 1 \mathrm{~cm}^{2}\right)$ a outra, em $9 \mathrm{ml} \mathrm{de}$ solução de triptona sal a partir da qual se fizeram as diluições decimais para se realizarem as demais determinações. Efetuou-se ainda colheita asséptica de músculo: $25 \mathrm{~g}$ para pesquisa de Listeria spp. e $10 \mathrm{~g}$ para as demais determinações.

Procedeu-se à contagem de microrganismos psicrotróficos por incorporação em meio Plate Count Agar $^{4}$ seguida de incubação durante 15 dias a $10-12^{\circ} \mathrm{C}$, de acordo com a NP 2307 (Microbiologia..., 1987), e à pesquisa de coliformes em meio líquido seletivo, caldo verde brilhante ${ }^{5}$, com incubação a $30 \pm 1^{\circ} \mathrm{C}$, durante 48 horas, segundo a NP 2164 (Microbiologia..., 1983). A partir dos tubos positivos para a pesquisa de coliformes (turvação do meio e produção de gás) fez-se novo inóculo em caldo verde brilhante e em água peptonada, que foi incubado a $44,5 \pm 0,5^{\circ} \mathrm{C}$, durante 48 horas, para pesquisa de $E$. coli, segundo a NP 2308 (Microbiologia..., 1986a). Após o período de incubação, os cultivos em caldo verde brilhante que se apresentavam turvos e com produção de gás em, pelo menos, um décimo do tubo de Durham e os cultivos em água peptonada

\footnotetext{
${ }^{1} \mathrm{Atago}^{\mathrm{IM}}$ - modelo N-10E - Tokio, Japão

${ }^{2}$ Crison ${ }^{\mathrm{TM}}$ - modelo MicropH2002 - Barcelona, Espanha.

${ }^{3}$ Oxoid (CM863B e SR142E) - Basingstoke, Hampshire Inglaterra.

${ }^{4}$ Difco (0479) - Detroit, EUA.

${ }^{5}$ Merck (1.05454) - Darmstadt, Alemanha.
} 
nos quais se detectou a produção de indol, foram considerados positivos. A pesquisa de Staphylococcus coagulase positivos foi efetuada em meio líquido selectivo, Chapman dupla concentração, para pesquisa em $1 \mathrm{~g}$ de produto e em $1 \mathrm{~cm}^{2}$ de superfície do pescado, e posterior isolamento em Baird Parker Agar (BP) ${ }^{6}$ adicionado de Egg Yolk Tellurite ${ }^{7}$ e de solução de sulfametazina. A pesquisa de Staphylococcus coagulase positivos em $0,01 \mathrm{~g}$ de produto e em $0,01 \mathrm{~cm}^{2}$ de superfície do pescado foi feita por inóculo direto em $\mathrm{BP}$ e incubação a $37^{\circ} \mathrm{C}$ por 48 horas, segundo a NP 2260 (Microbiologia..., 1986c). Após o isolamento das colônias típicas em $\mathrm{BP}$ procedeu-se à sua repicagem para meio líquido Brain Heart Infusion ${ }^{8}$ e incubação a $37^{\circ} \mathrm{C}$ por 24 horas, para posterior pesquisa de catalase e de coagulase (Microbiologia..., 1986c). A pesquisa de Listeria spp. foi realizada, por meio do método imunoenzimático Enzyme Linked Fluorescent Assay, no equipamento miniVIDAS ${ }^{9}$.

Realizou-se ainda a pesquisa de esporos de clostrídios sulfito-redutores na superfície do pescado, em meio de Viande Levure regenerado e adicionado de sulfito de sódio e alúmen de ferro, com incubação a $37 \pm 1^{\circ} \mathrm{C}$, durante cinco dias. As diluições semeadas foram previamente inativadas a $80 \pm 0,5^{\circ} \mathrm{C}$, durante 10 minutos (Microbiologia..., 1986b).

A análise de dados foi realizada por meio do programa Statistica $^{10}$. A significância das diferenças entre as médias foi avaliada pelo teste LSD.

\section{RESULTADOS E DISCUSSÃO}

Os resultados da análise sensorial das amostras obtidas em quatro diferentes estabelecimentos de venda ao público encontram-se na Tab. 1.

De acordo com a NP 2287 (Pescado..., 1985a), o peixe fresco pode classificar-se, quanto ao grau de frescor, nas categorias: extra $(\geq 2,7)$; A ( $\geq 2$ e $<2,7)$ e $\mathrm{B} \quad(\geq 1$ e $<2)$. Essas categorias correspondem às definições de pescado em ótimo, bom e estado de frescor satisfatório, constantes no Regulamento de Inspeção e
Fiscalização higiênico-sanitárias do pescado (Portaria..., 1976).

Em T1, o pescado foi classificado, nas categorias A e B, ou seja, o seu estado de frescor variou entre bom e satisfatório. $\mathrm{O}$ fato de não se ter encontrado pescado da categoria extra pode ser explicado por vários fatores relacionados com a manipulação a que o peixe esteve sujeito desde a captura até a sua comercialização em regiões do interior do país, como é o caso de Vila Real. Os valores obtidos no T2, após armazenamento em condições abusivas $\left( \pm 8^{\circ} \mathrm{C}\right)$, são reveladores de uma marcada diminuição do grau de frescor, encontrando-se alguns peixes impróprios para consumo, pois mesmo com resfriamento adequado pode ocorre perda de textura, conforme verificado por Suárez-Mahecha et al. (2007) Contudo, em termos médios, o pescado apresentava ainda um grau de frescor aceitável.

Nas Tab. 2, 3 e 4 são apresentados os resultados das determinações físico-químicas, ABVT, $\mathrm{pH}$ e IR, do pescado.

A determinação do ABVT é um método que permite estabelecer objetivamente se o pescado está ou não apto para consumo (Martin et al., 1997; Pons-Sánchez-Cascado et al., 2005) e deve ser utilizado nos casos em que o exame organoléptico suscite dúvidas. Relativamente à espécie estudada, o valor de ABVT a partir do qual se considera as amostras impróprias para consumo é de $35 \mathrm{mgN} / 100 \mathrm{~g}$ (Baixas-Nogueras et al., 2002).

As amostras no $\mathrm{T} 1$ encontravam-se dentro dos teores adequados (Tab. 2), pois o valor médio mais alto de ABVT encontrado foi $27,36 \mathrm{mgN} / 100 \mathrm{~g}$. No T2, os teores foram consideravelmente mais elevados, pois a temperatura a que o pescado foi mantido permitiu a multiplicação da microflora presente, nomeadamente de microrganismos psicrotróficos, parcialmente responsáveis pela degradação da fração azotada. No T2 os valores médios de ABVT foram característicos de pescado impróprio para consumo.

${ }^{6} 0768$, Difco (0768) - Detroit, Michigan, EUA.

${ }^{7}$ Difco (0779), Detroit, Michigan, USA.

${ }^{8}$ Difco (0286), Detroit, Michigan, USA.

${ }^{9}$ Modelo 99088, BioMérieux (modelo 99088), Marcy

l'etoile, França.

${ }^{10}$ Statsoft - versão 5.1, 1998 - Tulsa, EUA. 
Estado de frescor e qualidade higiênica...

Tabela 1. Análise sensorial (média + erro padrão) do pescado adquirido em diferentes estabelecimentos comerciais de Vila Real, expressa em graus de frescor (GF)

\begin{tabular}{ccccccc}
\hline Origem & Tempo & $\mathrm{N}^{\mathrm{o}}$ amostras & GF & Mínimo & Máximo & $\mathrm{CV}(\%)$ \\
\hline $\mathrm{A}$ & $\mathrm{T}_{1}$ & 6 & $2,1 \pm 0,16$ & 1,7 & 2,6 & 19 \\
$\mathrm{~B}$ & $\mathrm{~T}_{1}$ & 6 & $1,9 \pm 0,13$ & 1,6 & 2,5 & 16 \\
$\mathrm{C}$ & $\mathrm{T}_{1}$ & 5 & $2,0 \pm 0,05$ & 1,8 & 2,2 & 6 \\
$\mathrm{D}$ & $\mathrm{T}_{1}$ & 6 & $1,8 \pm 0,08$ & 1,5 & 2,1 & 11 \\
\hline $\mathrm{A}$ & $\mathrm{T}_{2}$ & 6 & $1,2 \pm 0,12$ & 0,8 & 1,5 & 25 \\
$\mathrm{~B}$ & $\mathrm{~T}_{2}$ & 6 & $1,1 \pm 0,11$ & 0,8 & 1,5 & 24 \\
$\mathrm{C}$ & $\mathrm{T}_{2}$ & 5 & $1,2 \pm 0,09$ & 1,0 & 1,5 & 16 \\
$\mathrm{D}$ & $\mathrm{T}_{2}$ & 6 & $1,0 \pm 0,1$ & 0,8 & 1,4 & 23 \\
\hline
\end{tabular}

$\mathrm{A}, \mathrm{B}, \mathrm{C}, \mathrm{D}=$ diferentes estabelecimentos de venda ao público; $\mathrm{T}_{1} \mathrm{e} \mathrm{T}_{2}=$ análise logo após e $48 \mathrm{~h}$ após aquisição, respectivamente; $\mathrm{CV}=$ coeficiente de variação.

Constatou-se, ainda, que os valores obtidos na análise sensorial não apresentavam diferenças significativas $(\mathrm{P} \geq 0,05)$ em função do estabelecimento comercial.

Tabela 2. Azoto básico volátil total (ABVT-mgN/100g), do pescado adquirido em diferentes estabelecimentos comerciais de Vila Real (média + erro-padrão)

\begin{tabular}{ccccccc}
\hline Origem & Tempo & $\mathrm{N}^{\mathbf{o}}$ amostras & ABVT & Mínimo & Máximo & $\mathrm{CV}(\%)$ \\
\hline $\mathrm{A}$ & $\mathrm{T}_{1}$ & 6 & $27,36 \pm 2,37$ & 19,87 & 33,77 & 21 \\
$\mathrm{~B}$ & $\mathrm{~T}_{1}$ & 6 & $24,19 \pm 2,01$ & 17,88 & 30,27 & 20 \\
$\mathrm{C}$ & $\mathrm{T}_{1}$ & 5 & $21,29 \pm 2,42$ & 15,80 & 29,72 & 25 \\
$\mathrm{D}$ & $\mathrm{T}_{1}$ & 6 & $20,60 \pm 2,68$ & 11,92 & 31,75 & 32 \\
\hline $\mathrm{A}$ & $\mathrm{T}_{2}$ & 6 & $45,46 \pm 4,64$ & 30,06 & 60,92 & 25 \\
$\mathrm{~B}$ & $\mathrm{~T}_{2}$ & 6 & $51,56 \pm 7,79$ & 30,87 & 87,33 & 37 \\
$\mathrm{C}$ & $\mathrm{T}_{2}$ & 5 & $41,09 \pm 3,38$ & 31,33 & 51 & 18 \\
$\mathrm{D}$ & $\mathrm{T}_{2}$ & 6 & $51,74 \pm 3,98$ & 40,26 & 68 & 19 \\
\hline
\end{tabular}

A, B, C, D= diferentes estabelecimentos de venda ao público; $\mathrm{T}_{1}$ e $\mathrm{T}_{2}=$ análise logo após e $48 \mathrm{~h}$ após aquisição, respectivamente; $\mathrm{CV}=$ coeficiente de variação.

Tabela 3. Unidades de pH (média + erro-padrão) do pescado adquirido em diferentes estabelecimentos comerciais de Vila Real

\begin{tabular}{ccccccc}
\hline Origem & Tempo & $\mathrm{N}^{\mathrm{o}}$ amostras & $\mathrm{pH}$ & Mínimo & Máximo & $\mathrm{CV}(\%)$ \\
\hline $\mathrm{A}$ & $\mathrm{T}_{1}$ & 6 & $6,31 \pm 0,07$ & 6,07 & 6,44 & 3 \\
$\mathrm{~B}$ & $\mathrm{~T}_{1}$ & 6 & $6,35 \pm 0,11$ & 6,08 & 6,73 & 4 \\
$\mathrm{C}$ & $\mathrm{T}_{1}$ & 5 & $6,36 \pm 0,06$ & 6,20 & 6,51 & 2 \\
$\mathrm{D}$ & $\mathrm{T}_{1}$ & 6 & $6,40 \pm 0,07$ & 6,16 & 6,55 & 2 \\
\hline $\mathrm{A}$ & $\mathrm{T}_{2}$ & 6 & $6,58 \pm 0,11$ & 6,30 & 6,97 & 4 \\
$\mathrm{~B}$ & $\mathrm{~T}_{2}$ & 6 & $6,59 \pm 0,15$ & 6,06 & 6,99 & 6 \\
$\mathrm{C}$ & $\mathrm{T}_{2}$ & 5 & $6,49 \pm 0,05$ & 6,35 & 6,65 & 2 \\
$\mathrm{D}$ & $\mathrm{T}_{2}$ & 6 & $6,67 \pm 0,1$ & 6,35 & 7,07 & 4 \\
\hline
\end{tabular}

$\mathrm{A}, \mathrm{B}, \mathrm{C}, \mathrm{D}=$ diferentes estabelecimentos de venda ao público; $\mathrm{T}_{1}$ e $\mathrm{T}_{2}=$ análise logo após e $48 \mathrm{~h}$ após aquisição, respectivamente; $\mathrm{CV}=$ coeficiente de variação. 
Tabela 4. Índice de refração (IR) do humor aquoso do pescado adquirido em diferentes estabelecimentos comerciais de Vila Real (média + erro-padrão)

\begin{tabular}{ccccccc} 
Origem & Tempo & $\mathrm{N}^{\mathrm{o}}$ amostras & $\mathrm{IR}$ & Mínimo & Máximo & $\mathrm{CV}(\%)$ \\
\hline $\mathrm{A}$ & $\mathrm{T}_{1}$ & 6 & $1,3362 \pm 0,0001$ & 1,3358 & 1,3365 & 0 \\
$\mathrm{~B}$ & $\mathrm{~T}_{1}$ & 6 & $1,3367 \pm 0,0002$ & 1,3363 & 1,3375 & 0 \\
$\mathrm{C}$ & $\mathrm{T}_{1}$ & 5 & $1,3363 \pm 0,00008$ & 1,3360 & 1,3365 & 0 \\
$\mathrm{D}$ & $\mathrm{T}_{1}$ & 6 & $1,3365 \pm 0,0002$ & 1,3360 & 1,3370 & 0 \\
\hline $\mathrm{A}$ & $\mathrm{T}_{2}$ & 6 & $1,3372 \pm 0,0002$ & 1,3365 & 1,3378 & 0 \\
$\mathrm{~B}$ & $\mathrm{~T}_{2}$ & 6 & $1,3373 \pm 0,0003$ & 1,3363 & 1,3385 & 0 \\
$\mathrm{C}$ & $\mathrm{T}_{2}$ & 5 & $1,3369 \pm 0,0002$ & 1,3363 & 1,3375 & 0 \\
$\mathrm{D}$ & $\mathrm{T}_{2}$ & 6 & $1,3372 \pm 0,0002$ & 1,3365 & 1,3380 & 0
\end{tabular}

A, B, C, D= diferentes estabelecimentos de venda ao público; $T_{1}$ e $T_{2}=$ análise logo após e $48 \mathrm{~h}$ após aquisição, respectivamente; $\mathrm{CV}=$ Coeficiente de variação.

Segundo Conde (1975), o pH do pescado fresco varia entre 6,6 e 6,8 e à medida que esse se deteriora os valores de $\mathrm{pH}$ aumentam e podem atingir 7,2. Oehlenschläger e Sörensen (1997) referem que o $\mathrm{pH}$ de um peixe fresco é menor que 7. Os valores médios de $\mathrm{pH}$ das amostras (Tab. 3) encontravam-se dentro dos limites considerados aceitáveis para peixe fresco, nos dois tempos considerados.

O IR do humor aquoso aumenta com a deterioração do pescado. De acordo com a tabela que relaciona o IR com a classificação de frescor (Farber, 1965), o pescado em ótimo estado de frescor apresenta valores de IR do humor aquoso entre 1,3347 e 1,3366 , em bom estado valores entre 1,3367 e 1,3380 , em estado satisfatório valores entre 1,3381 e 1,3393, e o que é reprovado valores iguais ou acima de 1,3394.

Pelo IR do humor aquoso (Tab. 4), todo o pescado analisado foi considerado apto para consumo. No T1, o pescado apresentou um grau de frescor que variou entre ótimo e bom e no T2, foi classificado na, sua generalidade, em bom estado de frescor.

Os valores obtidos nas análises fisico-químicas não diferiram entre si, segundo $\mathrm{o}$ estabelecimento comercial $(P \geq 0,05)$, semelhante ao resultado obtido com os parâmetros sensoriais.

Para avaliar as relações existentes entre os métodos subjetivos (análise sensorial) e objetivos (ABVT, IR e pH), os resultados, independentemente do tempo considerado, foram agrupados e analisados de duas formas distintas: em função da sua classificação em categorias pela análise sensorial (Tab. 5) e em função dos valores obtidos na determinação do ABVT (Tab. 6). A escolha da quantificação do ABVT como critério de agrupamento das amostras em detrimento do IR ou do $\mathrm{pH}$ deveu-se ao fato de ser esse o mais discriminativo.

Pela análise sensorial (Tab. 5), 85\% (39) das amostras foram consideradas aptas para consumo.

Tabela 5. Azoto básico volátil total (ABVT), índice de refração (IR) do humor aquoso e pH do pescado, para cada categoria de frescor de acordo com a análise sensorial (média + erro-padrão)

\begin{tabular}{cccc}
\hline $\begin{array}{c}\text { Análise } \\
\text { sensorial }\end{array}$ & $\begin{array}{c}\text { Categoria A } \\
(\mathrm{n}=11)\end{array}$ & $\begin{array}{c}\text { Categoria B } \\
(\mathrm{n}=28)\end{array}$ & $\begin{array}{c}\text { Reprovado } \\
(\mathrm{n}=7)\end{array}$ \\
\hline ABVT & $23,38 \pm 1,79 \mathrm{a}$ & $34,22 \pm 2,22 \mathrm{~b}$ & $60,30 \pm 5,20 \mathrm{c}$ \\
IR & $1,3363 \pm 0,00006 \mathrm{a}$ & $1,3368 \pm 0,00001 \mathrm{~b}$ & $1,3374 \pm 0,00003 \mathrm{c}$ \\
pH & $6,35 \pm 0,05 \mathrm{a}$ & $6,43 \pm 0,04 \mathrm{a}$ & $6,8 \pm 0,07 \mathrm{~b}$ \\
\hline
\end{tabular}

Médias seguidas por letras distintas na linha diferem entre si $(\mathrm{P}<0,001)$. 
Tabela 6. Análise sensorial (AS), índice de refração (IR) do humor aquoso e pH do pescado (média + erro-padrão), para cada categorias de acordo com o teor de azoto básico volátil total (ABVT)

\begin{tabular}{ccc} 
ABVT & $\begin{array}{c}\text { Aprovado } \\
(\mathrm{n}=26)\end{array}$ & $\begin{array}{c}\text { Reprovado } \\
(\mathrm{n}=20)\end{array}$ \\
\hline AS & $1,91 \pm 0,06 \mathrm{a}$ & $1,06 \pm 0,05 \mathrm{~b}$ \\
IR & $1,3365 \pm 0,0001 \mathrm{a}$ & $1,3371 \pm 0,0001 \mathrm{~b}$ \\
$\mathrm{pH}$ & $6,36 \pm 0,03 \mathrm{a}$ & $6,62 \pm 0,06 \mathrm{~b}$ \\
\hline
\end{tabular}

Médias seguidas por letras distintas na linha diferem entre si $(\mathrm{P}<0,05)$.

Os valores de ABVT e IR apresentaram diferenças altamente significativas $(\mathrm{P}<0,001)$ entre as categorias consideradas em função da análise sensorial. A determinação do ABVT e do IR do humor aquoso permitiu diferenciar as três categorias de frescor identificadas pela análise sensorial. Relativamente ao $\mathrm{pH}$, os valores obtidos no pescado classificado nas categorias de frescor A e $B$, pela análise sensorial, não foram diferentes entre si $(\mathrm{P} \geq 0,05)$. Observaram-se, no entanto, diferenças altamente significativas $(\mathrm{P}<0,001)$, entre os valores de $\mathrm{pH}$ do peixe apto para consumo (A e B) e do reprovado. $\mathrm{O} \mathrm{pH}$ parece ser o método menos eficiente na diferenciação das várias categorias de frescor do pescado.

Todos os métodos físico-químicos utilizados evoluíram no sentido inverso da análise sensorial, e apresentaram nos três ABVT $(\mathrm{r}=-0,80 ; \mathrm{P}<0,05)$, $\mathrm{pH}$ $(\mathrm{r}=-0,54 ; \mathrm{P}<0,05)$ e no IR do humor aquoso $(\mathrm{r}=$ $0,60 ; \mathrm{P}<0,05)$ correlação negativa significativa com $\mathrm{a}$ análise sensorial.

Apenas 57\% (26) das amostras seriam aprovadas em função dos critérios estabelecidos pela determinação do ABVT (Tab. 6). Este método parece ser o mais exigente na avaliação do frescor do pescado do que a análise sensorial. Os valores obtidos nas demais determinações apresentaram diferenças altamente significativas $(\mathrm{P}<0,001)$ entre as amostras classificadas como aprovadas e reprovadas em função da determinação do ABVT.

O pescado considerado impróprio para consumo pelo método do ABVT seria aprovado pelo IR e o pH (Tab. 5 e 6), uma vez que apresenta, em média, valores de $\mathrm{pH}$ de peixe fresco $(6,6)$ e IR do humor aquoso considerados de pescado em bom estado de frescor $(1,3371)$.

Na Tab. 7 são apresentados os resultados da pesquisa de microrganismos totais psicrotróficos na superfície e no músculo do pescado.

Segundo os padrões bacteriológicos de alimentos portugueses (Ribeiro, 1974) todas as amostras analisadas apresentavam teor de microrganismos psicrotróficos totais aceitáveis $(<7 \log \mathrm{UFC} / \mathrm{g}$ de músculo analisado).

O número de microrganismos psicrotróficos na superfície foi sempre maior que o encontrado no músculo, reflexo da influência da microflora ambiental e resultante da manipulação. Porém, não foram encontradas diferenças significativas $(\mathrm{P}>0,05)$ na contagem de microrganismos psicrotróficos entre as amostras provenientes de diferentes origens.

Tabela 7. Contagem de microrganismos totais psicrotróficos na superfície $\left(\log \mathrm{UFC} / \mathrm{cm}^{2}\right)$ e no músculo (log UFC/g) do pescado adquirido em diferentes estabelecimentos de Vila Real

\begin{tabular}{cccccccc}
\hline \multirow{5}{*}{ Superfície } & Origem & $\begin{array}{c}\mathrm{N}^{\circ} \mathrm{de} \\
\text { amostras }\end{array}$ & Média & Mínimo & Máximo & DP & CV(\%) \\
& $\mathrm{A}$ & 6 & 5,92 & 5,53 & 6,51 & 0,43 & 7,28 \\
& $\mathrm{~B}$ & 6 & 6,03 & 5,15 & 7,04 & 0,85 & 14,17 \\
& $\mathrm{C}$ & 5 & 5,41 & 4,45 & 6,44 & 0,80 & 14,77 \\
\multirow{5}{*}{ Músculo } & $\mathrm{D}$ & 6 & 5,85 & 5,17 & 6,61 & 0,64 & 10,87 \\
& $\mathrm{~A}$ & 6 & 5,08 & 3,74 & 5,94 & 0,94 & 18,44 \\
& $\mathrm{~B}$ & 6 & 5,28 & 3,74 & 6,32 & 0,89 & 16,94 \\
& $\mathrm{C}$ & 5 & 4,79 & 3,76 & 5,71 & 0,71 & 14,91 \\
\hline
\end{tabular}

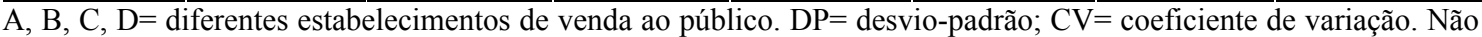
houve diferenças significativas entre as médias $(\mathrm{P}>0,05)$. 
Verificou-se correlação negativa significativa entre os valores da análise sensorial e o número de microrganismos psicrotróficos total presentes no músculo $(\mathrm{r}=-0,53 ; \mathrm{P}<0,05)$, ou seja, quanto maior o grau de frescor das amostras menor o número de microrganismos psicrotróficos presentes no músculo.

Os resultados referentes à pesquisa de coliformes, E. coli, Staphylococcus coagulase positivo, Listeria spp. e clostrídios sulfitoredutores, na superfície das amostras analisadas são apresentados na Tab. 8, os referentes à pesquisa dos mesmos microrganismos, exceto os clostrídios sulfito-redutores, no músculo encontram-se na Tab. 9.

Segundo os padrões bacteriológicos dos alimentos (Ribeiro, 1974), em pescado cru, as bactérias coliformes e E. coli deveriam estar ausentes, respectivamente, em $0,01 \mathrm{~g}$ e $0,1 \mathrm{~g}$ de músculo analisado. Sete amostras (30\%) apresentavam número de coliformes acima do aceitável. Não foi, no entanto, isolada $E$. coli (testemunha segura de contaminação de origem fecal) em nenhuma das amostras; o mesmo ocorreu com Listeria spp.

Tabela 8. Coliformes totais, E. coli, Staphylococcus coagulase positivo, clostrídios sulfito-redutores e Listeria spp. na superfície do pescado adquirido em diferentes estabelecimentos de Vila Real

\begin{tabular}{|c|c|c|c|c|c|c|c|c|c|}
\hline \multirow[b]{2}{*}{ Origem } & \multirow[b]{2}{*}{$\mathrm{N}^{\mathrm{o}}$ amostras } & \multicolumn{4}{|c|}{ Coliformes totais $\left(\mathrm{cm}^{2}\right)$} & \multirow[b]{2}{*}{ E. coli } & \multirow{2}{*}{$\begin{array}{l}\text { S. coag. }+ \\
\left(1 \mathrm{~cm}^{2}\right)\end{array}$} & \multirow{2}{*}{$\begin{array}{l}\text { Clostridios } \\
\text { sulfito- } \\
\text { redutores }\end{array}$} & \multirow[b]{2}{*}{ Listeria } \\
\hline & & 1 & 0,1 & 0,01 & 0,001 & & & & \\
\hline $\mathrm{A}$ & 6 & 2 & 1 & 2 & - & - & 1 & - & - \\
\hline $\mathrm{B}$ & 6 & - & 1 & 3 & 1 & - & - & - & - \\
\hline $\mathrm{C}$ & 5 & 2 & 1 & - & 1 & - & - & - & - \\
\hline $\mathrm{D}$ & 6 & 2 & 1 & - & 1 & - & 1 & - & - \\
\hline
\end{tabular}

$\mathrm{A}, \mathrm{B}, \mathrm{C}, \mathrm{D}=$ diferentes estabelecimentos de venda ao público.

Tabela 9. Coliformes totais, E. coli, Staphylococcus coagulase positivo e Listeria spp. no músculo do pescado adquirido em diferentes estabelecimentos de Vila Real

\begin{tabular}{cccccccccc}
\multirow{2}{*}{ Origem } & \multirow{2}{*}{$\begin{array}{c}\mathrm{N}^{\mathrm{o}} \mathrm{de} \\
\text { amostras }\end{array}$} & \multicolumn{9}{c}{$\mathrm{g}$} & $0,1 \mathrm{~g}$ & $0,01 \mathrm{~g}$ & $0,001 \mathrm{~g}$ & coli & S. coag. + & $\begin{array}{c}\text { Listeria } \\
(25 \mathrm{~g})\end{array}$ \\
\hline $\mathrm{A}$ & 6 & - & 3 & 2 & - & - & $2(1 \mathrm{~g})$ & - \\
$\mathrm{B}$ & 6 & 1 & 1 & 1 & 2 & - & - & - \\
$\mathrm{C}$ & 5 & 2 & 1 & - & 1 & - & - & - \\
$\mathrm{D}$ & 6 & 2 & 2 & 1 & - & - & - & - \\
\hline
\end{tabular}

$\mathrm{A}, \mathrm{B}, \mathrm{C}, \mathrm{D}=$ diferentes estabelecimentos de venda ao público.

Esporos de clostrídios sulfito-redutores encontravam-se ausentes em todas as análises efetuadas a partir de zaragatoas da superfície do pescado. Esses microrganismos, muitas vezes, são associados a uma contaminação de origem ambiental (Frazier e Westhoof, 1988; Gibson, 1995) e a sua ausência pode significar fraca contaminação com essa origem. Staphylococcus coagulase positivo foi isolado apenas no músculo (1g) de duas amostras provenientes do mesmo estabelecimento comercial. Dessas, uma apresentava o mesmo tipo de contaminação na superfície $\left(1 \mathrm{~cm}^{2}\right)$. Verificou-se, quando da aquisição das amostras, que o funcionário do estabelecimento não cumpria algumas das regras desejáveis de manipulação de alimentos, o que se enquadra na idéia genericamente aceita de que a presença desse microrganismo nos alimentos está, muitas vezes, relacionada com deficientes operações de manipulação (Inghan et al., 2000; Candlish et al., 2001).

\section{CONCLUSÕES}

O pescado fresco analisado, logo após aquisição, apresentou estado de frescor entre bom e satisfatório, independentemente do estabelecimento comercial. O método objetivo mais rigoroso e de eleição, sempre que houver dúvidas quanto ao grau de frescor do pescado, deve ser o ABVT. Relativamente às análises microbiológicas, em geral, as amostras apresentavam padrão aceitável. 


\section{AGRADECIMENTOS}

Ao Professor Doutor Luís Patarata, pela ajuda na análise dos resultados.

\section{REFERÊNCIAS BIBLIOGRÁFICAS}

BAIXAS-NOGUERAS, S.; BOVER-CID, S.; VECIANANOGUÉS, T. et al. Chemical and sensory changes in mediterranean hake (Merluccius merluccius) under refrigeration $\left(6-8{ }^{\circ} \mathrm{C}\right)$ and stored in ice. J. Agric. Food Chem., v. 50, p.6504-6510, 2002.

BAIXAS-NOGUERAS, S.; BOVER-CID, S.; VIDALCAROU, M.C. et al. Trimethylamine and total volatile basic nitrogen determination by flow injection/gas diffusion in mediterranean hake (Merluccius merluccius). J. Agric. Food Chem., v.49, p.1681-1686, 2001.

CANDLISH, A.A.G.; PEARSON, S.M.; AIDOO, K.E. et al. A survey of etnic foods for microbial quality and aflotoxin content. Food Ad. Contam., v.18, p.129-136, 2001.

CONDE, J.M.M. Guia del inspector veterinário titular: 1bromotologia sanitaria. Barcelona: Biblioteca Veterinária Aedos, 1975. p.190-260.

FARBER, L. Freshness tests. In: BORGSTROM, G. (Ed.) Fish as food. New York: Academic, 1965. v.IV, p.66-69.

FRAZIER, W.C.; WESTHOFF, D.C. (Ed). Food microbiology. 4.ed. New York: McGraw-Hill, 1988.

GIBSON, D.M. Hygiene and Safety of Seafood. In: RUITER, A. (Ed.). Fish and fishery products, composition, nutritive properties and stability. Guildford: $\mathrm{Cab}$ International, 1995. p. 243-260

HUSS, H.H. Assurance of seafood quality. FAO Fisheries Technical Paper 334, Roma, 1994. p.46-66.

INGHAN, A.C.; REYES, J.C.N.; SCHOELLER, N.P. et al. Potential use of presuntive enterococci and staphylococci as indicaters of sanitary conditions implant making hard Italiantype cheese. J. Food Prot., v.63, p.1697-1701, 2000.

MARTIN, R.E; COLLETE, R.L.; SLAVIN, J.W. Fish inspection, quality control, and HACCP. A global focus. Oregon State University, 1997. Disponível em <http://www.heads-up.net/ >.Acessado em: 1 Mar. 2007.

MARTIN, C.R.A. Practical food inspection. London: Lewis \& Co, 1978. p. 358-361.

MATOS, M.M.C. Métodos rápidos para análise do frescor do pescado. Vet. Tec., v.4, p.22-25, 1994.
MICROBIOLOGIA alimentar. Regras gerais para pesquisa de bactérias coliformes. Norma Portuguesa 2164. Lisboa: Instituto Português de Qualidade, 1983. 7p.

MICROBIOLOGIA Alimentar. Regras gerais para pesquisa de Escherichia coli. Norma Portuguesa 2308. Lisboa: Instituto Português de Qualidade, 1986a. 6p.

MICROBIOLOGIA Alimentar. Regras gerais para pesquisa de esporos de clostrídios sulfito-redutores. Norma Portuguesa 2262. Lisboa: Instituto Português de Qualidade, 1986b. 8p.

MICROBIOLOGIA Alimentar. Regras gerais para pesquisa de Staphylococcus aureus. Norma Portuguesa 2260. Lisboa: Instituto Português de Qualidade, 1986c. 11p.

MICROBIOLOGIA Alimentar. Regras gerais para contagem de microrganismos psicrotróficos. Norma Portuguesa 2307. Lisboa: Instituto Português de Qualidade, 1987.

NIELSEN, J. Sensory analysis of fish. In: THE FINAL MEETING OF THE CONCERTED ACTION EVALUATION OF FISH FRESHNESS - 1997, Nantes. [Anais...] Nantes, 1997. p.279-286.

OEHLENSCHLÄGER J.; SÖRENSEN, N.K. Criteria of fish freshness and quality aspects. In: THE FINAL MEETING OF THE CONCERTED ACTION - EVALUATION OF FISH FRESHNESS - 1997, Nantes. [Anais...] Nantes, 1997. p.30-35.

PESCADO. Classificação do frescor do peixe. Norma Portuguesa 2287. Lisboa: Instituto Português de Qualidade, 1985a. 5p.

PESCADO. Determinação do teor de azoto básico volátil total (ABVT). Método de Conway. Norma Portuguesa 2930. Lisboa: Instituto Português de Qualidade, 1985b. 5p.

PONS-SÁNCHEZ-CASCADO, S.; VIDAL-CAROU, M. C.; MARINÉ-FONT, A. et al. Influence of the freshness grade of raw fish on the formation of volatile and biogenic amines during the manufacture and storage of vinegar-marinated anchovies. J. Agric. Food Chem., v.53, p.8586-8592, 2005.

PORTARIA $\mathrm{n}^{\mathrm{o}}$ 559/76. Regulamento de inspeção e fiscalização higiênico-sanitárias do pescado. Lisboa: Diário da República $\mathrm{n}^{\circ}$ 210, I série B, 1976. p.2116-2125.

REGULAMENTO (CE) nº 2406 de 26 de novembro de 1996. Bruxelas: Jornal Oficial das Comunidades Européias, L 334, 1996. 15p.

RIBEIRO, A.M.R. Padrões bacteriológicos de alimentos portugueses. Rev. Microbiol., v.5, p.9, 1974.

SUÁREZ-MAHECHA, H.; BEIRÃO, L.H.; FRANCISCO, A. et al. Efeito do resfriamento sobre a textura post-mortem da carne do peixe matrinxã Brycon cephalus. Arq. Bras. Med. Vet. Zootec., v.59, p. 1067-1073, 2007. 